\title{
EDITORIAL
}

landra Maria Weirich da Silva Coelho (iD https://orcid.org/0000-0003-3513-962X

Instituto Federal de Educação, Ciência e Tecnologia do Amazonas

e-mail - iandra.coelho@ifam.edu.br

\section{A adoção de novas práticas de gestão editorial}

A Revista de Estudos e Pesquisas sobre Ensino Tecnológico (EDUCITEC) torna público seu volume 6 , dando continuidade à missão de divulgar a produção acadêmico-científica e proporcionar a geração de novos conhecimentos relacionados, principalmente, sobre o ensino-aprendizagem e os diferentes fatores que nele interferem. Com isso, visamos possibilitar ao leitor o desvelamento de elementos constituintes desse processo, com evidência aos problemas teóricos e empíricos, conceitos e movimentos efetivados em diferentes áreas e níveis da Educação Básica e Superior.

Para a apresentação desse volume, não seria possível deixar de mencionar o momento histórico que nossa sociedade está vivenciando, permeado por incertezas e suas consequências, questionamentos e desafios relacionados ao combate à pandemia causada pelo Corona Vírus (COVID-19), que em alguns casos, resultaram em perdas irreversíveis.

Em meio a esse contexto, também não poderíamos deixar de registrar nossos agradecimentos e reconhecer o envolvimento comprometido de todos que colaboraram para que pudéssemos publicar mais um volume da revista. Agradecimentos especiais aos autores, que não mediram esforços para atender às solicitações do Corpo Editorial da Revista; aos pareceristas pelas valiosas contribuições; à equipe Técnica da Revista Educitec, pelo intenso trabalho realizado; aos professores do Programa de Pós-Graduação em Ensino Tecnológico e à Diretoria de Pesquisa e Pós-graduação que vem atuando na colaboração e apoio institucional dos processos editoriais para que a Revista possa alcançar seus objetivos e potencializar o acesso dos leitores à produção de novos conhecimentos.

Com a adoção de novas linhas temáticas, a Educitec passou a publicar propostas, a partir de intervenções teóricas e práticas, relacionadas a processos formativos para professores; criação, aplicação e avaliação de meios e recursos pedagógicos para a otimização de conhecimentos específicos para o processo de ensino-aprendizagem, atrelados principalmente às tecnologias; concepção, elaboração e metodologias empregadas na construção de produtos educacionais, bem como pesquisas que versam sobre o desenvolvimento da ciência da área do ensino, permitindo reflexões 
e debates, frutos dos resultados das pesquisas apresentadas e de suas possibilidades formativas.

Com o intuito de continuar efetivando mudanças significativas, este volume passou a inaugurar uma nova fase da Educitec, com adequação de algumas políticas editoriais e melhorias contínuas que demonstram o constante trabalho e compromisso com a pesquisa e divulgação científica, refletidos pelos editores anteriores e atual.

A fim de elevar a qualidade da revista Educitec e alcançar melhores níveis de avaliação periódica da Capes, a nova equipe tem adotado uma metodologia diferenciada e um conjunto de procedimentos, no âmbito organizacional, de conteúdo e design, tais como: i) composição de quatro linhas temáticas que visam ampliar as discussões referentes ao(s) Processos Formativos de Professores, Processos e Recursos para o Ensino, Produtos Educacionais e Metodologias para sua Elaboração e Desenvolvimento da ciência da área do ensino; ii) ampliação dos Conselhos Editoriais (nacional e internacional); iii) composição de nova equipe técnica (Projeto Gráfico e Diagramação da revista, Designer/ Webdesigner, Assistente Editorial, Revisores de Língua Portuguesa e Língua Inglesa); iv) elaboração de novos manuais para avaliadores e autores; v) adoção de nova capa e layout do periódico; vi) adequação do formulário de avaliação; vii) elaboração de novos templates para a submissão de artigos científicos; viii) ampliação do banco de avaliadores Ad hoc; ix) fomento à divulgação da revista, e x) ampliação das candidaturas para participação de bancos de indexação nacionais e internacionais.

Um dos procedimentos a ser destacado é a constituição de um Corpo Técnico Editorial da Educitec, que passou a contar com alguns alunos egressos para auxiliar no processo organizacional, oriundos do Mestrado Profissional em Ensino Tecnológico (MPET), e recentemente transformado em Programa de Pós-Graduação em Ensino Tecnológico (PPGET), devido à aprovação, em novembro de 2019, do Curso de Doutorado Profissional em Ensino Tecnológico do IFAM, considerado um marco para a Região Norte.

Outra assertiva importante refere-se à inclusão de servidores da instituição nesse Corpo Técnico, oriundos das unidades do interior do estado, levando em conta a necessidade da inter-regionalização em tempos de globalização, com o intuito de potencializar a política de fortalecimento das identidades culturais regionais e locais, e estimular novos modelos comunicacionais, incentivando a participação dos servidores dos campi do interior do estado do Amazonas em atividades relacionadas à pesquisa e publicação científica.

Em 2020, também passamos a adotar alguns procedimentos inovadores com relação à publicação desse periódico, com o intuito de promover [...] rapidez no processo de comunicação e disponibilização das pesquisas, com inúmeras vantagens para os usuários de informação científica: pesquisadores, estudantes, leitores, editores e agências de financiamento" (SciELO, 2018). Para tanto, aderimos à publicação na modalidade de fluxo contínuo, alinhando a Revista Educitec a uma tendência internacional. Nesse modelo, os artigos científicos são disponibilizados à medida que são aprovados pela equipe editorial e o processo de editoração é finalizado, sem a necessidade de aguardar o prazo das edições seriadas. Dessa forma, a cada ano, um único volume será publicado, no qual serão adicionados os artigos aprovados.

Essa atualização também traz mudanças na forma de citação do artigo da Revista Educitec, que deixa de indicar o número da edição e a paginação sequencial. A partir de 2020, para fazer referência a um artigo, além do DOI, passamos a utilizar um 
número identificador eletrônico, denominado eLocation-id (código de números, precedido pela letra "e").

Com base na filosofia do Acesso Aberto, a Revista Educitec também passou a ter um perfil no Google Acadêmico para fins de divulgação e avaliação dos artigos publicados, combinando produtividade e impacto. Assim, por meio das ferramentas de indexação do Google é possível avaliar o impacto através de um eficiente índice de métricas, que permite a identificação das listas de referências, verificação e evolução do número de citações dos artigos em um determinado período, contagem do índice de citação dos artigos publicados, verificação dos perfis dos autores, visualização do Índice h, entre outras funcionalidades.

Outro aspecto discutido nessa nova proposta editorial refere-se à internacionalização, tendência que se consolida em diferentes instituições de ensino e pesquisa. As estratégias de internacionalização visam ampliar a contribuição da Educitec para a divulgação de pesquisas na área de Ensino, voltadas tanto para o cenário nacional, como a comunidade internacional de pesquisadores. Por tal motivo, as primeiras estratégias adotadas foram a publicação de artigos originais em português, vertidos para a língua inglesa, e potencial inclusão da Educitec em novos bancos de indexadores internacionais, a fim de seguir o plano de internacionalização da Revista.

Entre os procedimentos futuros, buscamos novos caminhos e possibilidades em relação ao modelo tradicional do processo editorial, a fim de trazer inovações na editoração científica da Revista Educitec. Isso implica incluir, de forma gradual, o processo de adoção da ciência aberta, um movimento disruptivo que visa à adoção progressiva de formas mais abertas de editoração (PACKER; SANTOS, 2019). Um dos principais caminhos foi iniciado no contexto desse movimento: a abertura para a publicação contínua.

Caminhos futuros incluem outras linhas de ação, tais como, a identificação do nome do editor responsável pela avaliação e aprovação do manuscrito e a possível publicação dos pareceres dos artigos aprovados (encaminhados pelos revisores Ad hoc) em formato de textos de comunicação científica, com inserção de DOI. Tais procedimentos são recomendados pela Scielo (2018) e Associação Brasileira de Editores Científicos (ABEC) e estão relacionados a tendências e boas práticas de gestão editorial de periódicos científicos, que visam práticas mais abertas e transparentes e privilegiam a natureza colaborativa, buscando o aprimoramento do modo de fazer e publicar os resultados das pesquisas científicas. (SILVEIRA; SILVA, 2020).

A adoção das medidas mencionadas e as linhas de ação futuras buscam aumentar a visibilidade da Educitec, fortalecer a produção divulgada e fomentar a adoção dos padrões e a sistematização de novas práticas editoriais de publicação científica. Para tanto, reiteramos o compromisso com uma trajetória pautada na efetiva divulgação de pesquisas científicas na área de Ensino, desde uma perspectiva inovadora, corroborando as palavras de Fernando Teixeira de Andrade de que "É o tempo da travessia; e se não ousarmos fazê-la, teremos ficado, para sempre, à margem de nós mesmos." 


\section{Referências}

PACKER, A.L.; SANTOS, S. Ciência Aberta e o novo modus operandi de comunicar pesquisa. Boletim Informativo da Sociedade Brasileira de Ciência do Solo. 2019, v. $45, \quad$ n. $1, \quad$ p. 17-24. Disponível em: https://www.sbcs.org.br/wpcontent/uploads/2019/06/Boletim-SBCS-Volume-45-N\%C3\%BAmero-1.pdf. Acesso em: 20 mar. 2020.

SciELO. Guia para publicação contínua de artigos em periódicos indexados no SciELO. 2018a. Disponível em: http://www.scielo.org/local/lmage/guiarpass.pdf. Acesso em: 15 mar. 2020.

SciELO. Linhas prioritárias de ação 2019-2023 [online]. SciELO 20 Anos. 2018b. Disponível em: https://www.scielo20.org/redescielo/wpcontent/uploads/sites/2/2018/09/Líneas-prioritaris-de-acción-2019-2023_pt.pdf. Acesso em: 20 mar. 2020.

SILVEIRA, L.; SILVA, F. C. C. (Org.). Gestão Editorial de Periódicos Científicos: tendências e boas práticas. Florianópolis: BU Publicações/UFSC, Edições do Bosque/UFSC, $2020 . \quad$ Disponível

em: https://repositorio.ufsc.br/handle/123456789/208691. Acesso em: 02 jun. 2020.

Recebido: 08/06/20

Aprovado: 09/06/20

Como citar: COELHO, I. M. W. S. A adoção de novas práticas de gestão editorial. Revista de

Estudos e Pesquisa sobre Ensino Tecnológico (EDUCITEC), v. 6, e132220, 2020.

Direito autoral: Este artigo está licenciado sob os termos da Licença Creative Commons-

Atribuição 4.0 Internacional. 